\title{
GERAKAN PESANTREN KOMBOS DI MANADO DALAM MERESPON ARUS POST-NASIONALISME
}

\author{
Oleh: \\ Almunauwar Bin Rusli ${ }^{1}$ \\ Universitas Islam Indonesia Yogyakarta \\ Email : almunauwar_b.rusli@yahoo.com
}

\begin{abstract}
Pesantren Kombos was established in 1977. From the new order era to reformation, pesantren Kombos have contributed to socio-religious life in multicultural society in Manado (Islam 128.483 \%, Christian 254.912 \%, Catholic 20.602 \%, Hindu $692 \%$, Buddha $2.224 \%$, and Konghucu $499 \%$ ). Since the 9/11 attacks in the United States and the Bali bombings in October 2002 in Indonesia, pesantren have been the focus of international attention. Foreigner called Islamic education as breeding grounds for terrorist. Acts of radicalism and terrorism (postnasionalism) commited by Abu Bakar Baa'syir and Abdullah Sungkar has made pesantren become training institutions of jihad against the West under Jamaah Islamiyah group as Sidney Jones's observation. Other religions are taught from the perspective of a particular religion. This model of religious education has been challenged especially after the 1998 political reform. Through literature study, the result of this research indicates that the situation in Manado looks stable even not trapped in actions of radicalism and global terrorism. To respond postnasionalism, pesantren Kombos in Manado build three major movements, namely ideology-political movement, demographic-accomodative movement, and programmatic-assosiative movement. Those three movements are using humanist, rational, and functional approach. Thus, in summary, pesantren Kombos has a cosmopolitan character that is actualized in the system Torang Samua Basudara and $\mathrm{Si}$ тои Tiтои Tитои Tou.
\end{abstract}

Keywords : Movement, Pesantren Kombos, Postnasionalism

\footnotetext{
${ }^{1}$ Almunauwar Bin Rusli, peneliti terkait isu-isu pendidikan Islam kontemporer di Asia Tenggara khususnya Indonesia. Pada bulan November 2014-Maret 2015 diutus sebagai pengajar tamu di Munithi Chumchon Islam Seksa Foundation School, Pattani, Thailand Selatan . Sekarang sedang menekuni kajian bersama Pusat Studi Sosial Asia Tenggara (PSSAT) Universitas Gadjah Mada Yogyakarta dan Institute of Southeast Asia Islam (ISAIS) UIN Sunan Kalijaga Yogyakarta. Pada 22 Februari-03 Maret 2016 mendapat sponsor field research terkait Lembaga Pendidikan Islam di Singapore dari Wisconsin Madison University, USA. Email : almunauwar_b.rusli@yahoo.com.
} 


\section{Pendahuluan}

Pesantren Kombos adalah nama lain dari Pondok Karya Pembangunan. Didirikan secara resmi pada tanggal 21 Juli 1977 saat presiden Soeharto berkuasa. Pesantren kecil yang terletak di Jl. Arie Lasut, Kombos Timur, Kecamatan Singkil, Manado, Sulawesi Utara ini mendapat persetujuan juga oleh Gubernur Hein Victor Worang. Beliau merupakanseorang Kristen Protestan yang sering melakukan dialog sosialkeagamaan dengan Mantan Menteri Agama RI, Mukti Ali 1976 silam. Barangkali, di sinilah awal mula terjadinya negosiasi pusat-daerah berdasarkan corak "mutual understanding-mutual interest"agar pesantren diberikan ruang di Manado guna mentransmisikan pengetahuan agama, memelihara tradisi Islam sekaligus memproduksi ulama. Sedangkan bagi umat Kristen diberikan ruang lebih atau semacam legitimasi agar tetap mengendalikan sistem politik lokal dengan identitas keminahasaan mereka.Jika dilihat ke belakang,pada 1854 sudah ada taman pengajian di Kampung Islam dengan memberikan pengajaran kepada anak-anak yang berumur enam tahun ke atas. Hingga akhir masa kolonial pun telah berdiri sekolah formal, yaitu Sekolah Dasar Muhammadiyah di Kampung Arab (1934) dan di Sario Titiwungan (1938), Sekolah Dasar Subililhudah di Kampung Arab, Sekolah Dasar Islamiyah di Kampung Ketang Tua, dan Sekolah Dasar Partai Nahdlatul Syafieiyah di Sario Titiwungan. ${ }^{2}$

Keberadaan pesantren Kombos dimobilisasi untuk kepentingan kaderisasi umat Islam di Manado maupun pendatang. Targetnya, para santri menjadi

\footnotetext{
2 Ilham Daeng Makello, Kota Seribu Gereja : Dinamika Keagamaan Dan Penggunaan Ruang Di Kota Manado,(Yogyakarta : Penerbit Ombak, 2010), h.109
}

aset pembangunan bangsa yang bertakwa, cakap, dinamis dan terampil sesuai citacita pembangunan nasional. Awalnya, nama formal pesantren ini adalah Lembaga Pendidikan Islam (LPI). Sebab, secara teologis, masyarakat Manado mayoritas beragama non-Muslim. ${ }^{3}$ Sehingga, penggunaan simbol Islam kepada pesantren harus diciptakan, diatur lalu disebarluaskan untuk merepresentasikan perbedaan dengan lembaga-lembaga pendidikan yang banyak dikembangkan oleh kaum Nasrani.Meski demikian, proses representasi lembaga pendidikan ini tidak melahirkan jurang dikotomi antar agama

\footnotetext{
${ }^{3}$ Badan Pusat Statistik Kota Manado merilis data terkait jumlah penduduk menurut kecamatan dan agama yang di anut di Kota Manado, 2010. Untuk Kecamatan Malalayang, pemeluk Islam (9.042), Kristen (41.648), Katolik (3.403), Hindu (177), Budha (147) dan Konghucu (54). Untuk Kecamatan Sario, pemeluk Islam (5.495), Kristen (15.659), Katolik (1.683), Hindu (22), Budha (122), dan Konghucu (48). Untuk Kecamatan Wanea, pemeluk Islam (8.667), Kristen (45.248), Katolik (2.655), Hindu (155), Budha (133), dan Konghucu (17). Untuk Kecamatan Wenang, pemeluk Islam (10.203), Kristen (18.353), Katolik (2.188), Hindu (35), Budha (722), dan Konghucu (136). Untuk Kecamatan Tikala, pemeluk Islam (23.574), Kristen (40.642), Katolik (4.389), Hindu (156), Budha (477), dan Konghucu (138). Untuk Kecamatan Mapanget, pemeluk Islam (11.59), Kristen (36.732), Katolik (4.386), Hindu (84), Budha (166) dan Konghucu (43). Untuk Kecamatan Singkil, pemeluk Islam (26.12), Kristen (19.619), Katolik (572), Hindu (17), Budha (261), dan Konghucu (28). Untuk Kecamatan Tuminting, pemeluk Islam (26.981), Kristen (23.152), Katolik (1.156), Hindu (46), Budha (211), dan Konghucu (33). Untuk Kecamatan Bunaken, pemeluk Islam (6.811), Kristen (13.859), Katolik (151), Hindu (-), Budha (5), dan Konghucu (2). Dari komposisi ini dapat ditotal bahwa Islam di Manado sebanyak 128.483, Kristen 254.912, Katolik 20.602, Hindu, 692, Budha 2.224, dan Konghucu 499. Dengan demikian, masyarakat multikultural di Manado benar-benar menjadi modal yang sangat besar untuk menciptakan stabilitas politik maupun pendidikan.

Lihat http://manadokota.bps.go.id/linktabel statis/view/id/34. Diakses Selasa 06 September 2016.
} 
dan etnis di Manado apalagi sampai dimanfaatkan gerakan Islam transnasional guna menyeragamkan semua pranata kehidupan publik yang majemuk. Indikasi tersebut dapat dicermati selama 39 tahun pesantren Kombos masih tetap bertahan karena watak lokalitasnya yang inklusif serta tidak terlepas dari peran besar masyarakat muslim setempat termasuk pengaruh sosok charismatic leader di pesantren Kombos yaitu KH. Rizali M. Noor ${ }^{4}$. Gambaran awal tentang pesantren Kombos ini tentu sangat berbeda dengan dinamika yang dialami pesantren $\mathrm{Al}$ Mukmin Ngruki di Solo.

Sejak serangan 9/11 di Amerika Serikat dan bom Bali pada bulan Oktober 2002 di Indonesia, pesantren telah menjadi fokus perhatian internasional. Beberapa pemuda bertanggung jawab atas serangan di Bali, di mana ada lebih dari dua ratus orang meninggal dunia. Diantara pemuda itu merupakan siswa pada sebuah pesantren di Jawa Timur dan memiliki hubungan dengan Pesantren AlMukmin di Jawa Tengah. ${ }^{5}$ Al-Mukmin adalah rumah dari Abu Bakar Baa'syir, seorang sarjana Islam senior yang diduga telah menjadi pemimpin spiritual Jamaah Islamiyah (JI), sebuah organisasi bawah tanah yang memiliki keterlibatan dalam kampanye pengeboman dan teror sejak

\footnotetext{
${ }^{4}$ KH Rizali M Noor lahir pada 27 Oktober 1950. Beliau berasal dari Barabai, Ibu Kota Kabupaten Hulu Sungai Tengah, Provinsi Kalimantan Selatan. Berdasarkan Surat Keputusan Gubernur Sulawesi Utara, Olly Dondokambey No. 91 a Tahun 2016, K.H. Rizali M. Noor ditunjuk sebagai pembina kerohanian Islam serta penanggung jawab pelayanan ibadah di lingkungan Kantor Gubernur Sulawesi Utara.

5 Mereka adalah Fathur Rahman al-Gozi, Abu Jibril Abdurrahman, Taufik Abdul Halim, Faiz Abu Bakar Bafana, Agus Dwikarna, Tamsil Linrung dan Abdul Jamal Balfas. Lihat Noorhaidi Hasan, Laskar Jihad : Islam, Militansi, dan Pencarian Identitas di Indonesia Pasca-Orde Baru, (Jakarta : LP3ES, 2008), h.15
}

tahun 2000. ${ }^{6}$ Pada September 2003, Journal of Asian Affairs menyatakan pesantren diIndonesia persis seperti madrasah di Pakistan. "Like Pakistan madrassa, there exists anentire education system, the pesantren, which is independent of the government and provide with Islamic fertile ground to train the children of the poor in the mould of radical Islam". ${ }^{7}$ Pernyataan ini seakan menguatkan satu postulat, "As is the state, so is the school. And what you want in the state, youmust put into the school".

Mengutip International Crisis Group (ICG), pesantren Al-Mukmin Ngruki ditetapkan sebagai pusat jaringan muslim militan di Indonesia yang secara internasional merupakan jaringan alQaeda. Gerakan Jemaah Islamiyah lalu ditangkap kepolisian Indonesia. Jamaah Islamiyah adalah organisasi yang dirintis Abdullah Sungkar dan Abu Bakar Ba"asyir sejak 1992 dengan basis gerakan Darul Islam dan dinyatakan resmi berdiri tahun 1996 di Malaysia. Mereka mengakui memiliki hubungan dengan Osama bin Laden, Mujahidin Afghanistan dan Moro selama kurun waktu 1985-2000 dalam hal ideologispolitis, dan bukan dalam struktur organisasi. Demikian pula keterlibatan mereka dalam konflik Maluku, Ambon, dan Poso. ${ }^{8}$ Dalam artikel, "Al Qaeda in Southeast Asia : the case of the Ngruki Network in Indonesia", Sidney Jones mengatakan bahwa kebanyakan orang

\footnotetext{
${ }^{6}$ Robert W. Hefner, Making Modern Muslims: The Politics of Islamic Education in Southeast Asia, (Honolulu : University of Hawaa'i Press, 2009), h. 1

7 Arief Subhan, Lembaga Pendidikan Islam Indonesia Abad ke-20 : Pergumulan antara Modernisasi dan Identitas, (Jakarta : Kencana, 2012), h. 3

${ }^{8}$ Umar Abduh (editors), Konspirasi Intelijen \& Gerakan Islam Radikal, (Jakarta : Center for Democracy and Social Justice Studies, 2003), h.1
} 
yang melakukan tindakan teror di tanah air memiliki muara ke Pesantren $\mathrm{Al}$ Mukmin Ngruki. Analisis Sidne Jones ini perlu direnungkan bersama, mengingat Indonesia dikenal dengan "the meeting place of world religion". Jika penafsiran agama disalahartikan untuk kepentingan kelompok tertentu saja tanpa mempertimbangkan asas-asas multikulturalisme bangsa, maka fatal akibatnya.

Genealogi pesantren Kombos sebetulnya bermuara kepada suasana pendidikan Islam di Jawa sebagai "ibukota" pesantren Indonesia. Karena, KH. Rizali M. Noor sendiri sempat belajar di Jurusan Tarbiyah IAIN Sunan Kalijaga Yogyakarta sejak Orde Baru.Tapi, di tengah perjalanan, ternyata terjadi perbedaan arah terkait bagaimana sikap masing-masing institusi pesantren dalam memaknai dimensi nasionalisme dan religiusitas terkait sistem kehidupan berbangsa serta bernegara. Kajian ini berupaya untuk meninjau kembali proses sosial-politik, ideologi dan sepak terjang Abdullah Sungkar serta Abu Bakar Baa'syir sebagai pimpinan pesantren AlMukmin Ngruki. Kemudian membandingkannya dengan gerakan yang dilakukan pesantren Kombos di Manado dalam merespons arus postnasionalisme tersebut. Kajian ini menggunakan penelitian pustaka melalui pendekatan komparatif. Sehingga, diharapkan dapat berkontribusi dalam wacana pengembangan konsep Dar alAhdi wa al-Syahadah.

\section{Pesantren Al-Mukmin Ngruki: Melacak Akar Postnasionalisme}

Pesantren Al-Mukmin didirikan pada tahun 1972 oleh Ketua DDII Jawa Tengah, Abdullah Sungkar. Di antara pendirinya adalah lulusan Gontor bernama Abu Bakar Baa'syir. Sungkar, Baa'syir dan seluruh rekan mereka menentang keras rezim Suharto karenadianggap sebagai anti-Islam.
Mereka sangat dipengaruhi oleh pemikiran Ikhwanul Muslimin. Pengaruh ini dalam kasus tertentu tercermin pada pengajaran sejarah Islam dan doktrin di pesantren Al-Mukmin. Kurikulum pengajaran terkait erat dengan materi Salafi termasuk Ikhwanul Muslimin?. Lahirnya Pesantren Al-Mukmin Ngrukidilatarbelakangi oleh kebutuhan kader muballigh dalam rangka pemurnianajaran Islam dari pengaruh budaya lokal yang dianggap menyimpang dan membendung Kristenisasi. Pesantren Al-Mukmin wajib mencetak calon ulama yang siap berjihad fi sabilillah melalui dakwah untuk menegakkan syariah Islam secara kaffah. Bagi Al-Mukmin, Islam bukan hanya terbatas pada keyakinan melainkan harus menjadi ideologi pergerakan (Islamisme).

Akhir tahun 1970 hingga 1980-an adalah waktu yang sangat berarti bagi Sungkar dan Baa'syir untuk mengonsolidasikan kekuatan di Solo raya, karena pada tahun itu Sungkar memegang kendali atas DI di wilayah Surakarta. ${ }^{10}$ Pada era Orde Baru tersebut

\footnotetext{
9 Martin van Bruinessen, "Tradisionalist and Islamist Pesantrens in Contemporary Indonesia" dalam Farish A. Noor, Yoginder Sikand \& Martin van Bruinessen (editors), The Madrasah in Asia : Political Activism and Transnational Linkages, (Amsterdam : Amsterdam University Press, 2008), h. 231-232
}

${ }^{10}$ Salah satu kekuatan mereka dalam mengusung semangat postnasionalisme adalah melalui radio. Radio ABC dan Radio Dakwah Islamiyah (RADIS) didirikan oleh dua tokoh pengkhotbah ajaran Islam, Abdullah Sungkar dan Abu Bakar Baa'syir. Stasiun radio itu terletak di kompleks Masjid Al-Mukmin yang berarti bahwa hal tersebut terkait erat dengan Pesantren Al-Mukmin Ngruki. Pada tahun 1975, siaran Radio itu dilarang oleh rezim Orde Baru karena alasan politik. Tindakan ini menunjukkan pengaruh signifikan antara politik dan agama dalam kehidupan sosial. Beberapa pengamat mencatat, rezim Orde Baru mencoba untuk mengontrol arus informasi dengan memonopoli media cetak dan media elektronik. Media menjadi alat kontrol politik sekaligus menjaga stabilitas. Pelarangan terhadap RADIS merupakan 
Sungkar juga sangat aktif mengkampanyekan gerakan anti Pancasila yang dijadikan oleh Soeharto sebagai asas tunggal semua perkumpulan. ${ }^{11}$ Sungkar dan Baa'syir kemudian berhasil mendirikan Jama'ah Islamiyah. Ideologi yang mereka gunakan adalah ideologi Salafi Jihadi. JI menganggap rezim Orde Baru sebagai musuh yang harus diperangi karena sangat menindas kepentingan umat Islam, yaitu dengan menjadikan Pancasila sebagai asas tunggal dalam kehidupan bernegara serta bersifat represif terhadap kekuatan- kekuatan lain yang mengancam kekuasaannya. Umat Islam pun tidak dapat bebas berbicara mengkritik pemerintah. Orde Baru dianggap sebagai käfir mahally, yaitu menjalankan sistem kekuasaan yang tidak Islami dan menjadikan ideologi selain syariat Islam sebagai dasar negara.

Menurut Vedi R. Hadiz, begitu berkuasa, Orde Baru dengan cepat mengambil kebijakan yang keras terhadap organisasi Islam secara umum. Sebab, setelah komunis tersingkir, Islam politik menjadi satu-satunya kekuatan di Indonesia yang memiliki potensi untuk memobilisasi diri. Islam politik akan menentang logika dasar Orde Baru yang memulai pembangunan kapitalis di atas basis stabilitas sosial yang muncul melalui politik demobilisasi masyarakat secara luas. ${ }^{12}$ Setelah runtuhnya Orde

bukti nyata bagaimana negara mencoba mengontrol aktivitas dakwah secara serius. Lihat Sunarwoto, "Dakwah radio in Surakarta : A contest for Islamic Identity", dalam Jajat Burhanuddin and Kees van Dijk (editors), Islam in Indonesia : Contrasting Images and Interpretation, (Amsterdam : Amsterdam University Press, 2013), h.197

\footnotetext{
${ }^{11}$ Muzayyin Ahyar, Membaca Gerakan Islam Radikal dan Deradikalisasi Gerakan Islam, Jurnal Walisongo, Volume 23, Nomor 1, Mei 2015, h.10

${ }^{12}$ Fahmi Sallataholy, Pelabelan Gerakan Radikal Bagi Kelompok Keagamaan Dalam Islam : Studi
}

Baru, Jamaah Islamiyah mulai memanfaatkan momentum reformasi sebagai kendaraan untuk memasarkan ideologi postnasionalisme juga aksi mereka ke ruang publik melalui kekuatan tim kerja yang sudah dibagi ke beberapa wilayah. Noorhadi menjelaskan, selain mengecam sistem pemerintahan Indonesia, mereka menawarkan syariah sebagai alternatif negara. Mereka membawa Islam ke arah diskursif untuk melawan ideologi lain. Mereka ingin ajaran Islam kaffah harus diterapkan pada sistem politik, sosial,ekonomi dan budaya. $^{13}$

Jamaah Islamiyah sebagai tanzim sirri (organisasi rahasia) konseptornya adalah Abu Rusdan. Konsep itu disusun dalam suatu Pedoman Umum Perjuangan AlJamaah Al-Islamiyah (PUPJI) yang dirumuskan kelompok Abu Rusdan di Jawa dan kemudian draftnya dikirim ke Abdullah Sungkar dan Abu Bakar Ba'asyir di Malaysia. Di Malaysia konsep ini dibahas dalam rapat yang di antaranya diikuti oleh Mukhlas, Abu Fatih, Hambali, dan Adung. Tujuan Jamaah Islamiyah tetap untuk membentuk negara Islam sesuai dengan yang tertera ditujuan utama Darul Islam. Namun, Jamaah Islamiyah tidak setuju dengan organisasi Darul Islam yang dianggap tidak logis karena mirip organisasi negara namun tidak menguasai teritorial. Sebagai alternatif, Jamaah Islamiyah membentuk organisasi yang lebih fleksibel. Rujukannya adalah konsep jamaah Islamiyah di Mesir. ${ }^{14}$ Dari sini, jelas bahwa Jamaah Islamiyah Indonesia memiliki jaringan kuat dengan

Relasi Agama dan Negara di Indonesia, Dialog, Jurnal Penelitian dan Kajian Keagamaan, Vol. 35, No. 1, Juni 2012, h. 7

13 Noorhaidi Hasan, Laskar Jihad : Islam, Militansi, dan Pencarian Identitas di Indonesia Pasca-Orde Baru, h. 17

14 As'ad Said Ali, Al-qaeda : Tinjauan SosialPolitik, Ideologi dan Sepak Terjangnya, (Jakarta : LP3ES, 2014), h. 167 
Timur Tengah, dimana mereka terikat pada semangan pan-Islamisme. Jaringan transnasional ini turut mengkonstruksi munculnya gejala radikalisme karena demokrasi di Indonesia dipandang tidak relevan.

Ada tiga kecenderungan umum terjadinya radikalisme. Pertama, radikalisme merupakan respons terhadap kondisi yang sedang berlangsung. Kedua, radikalisme tidak berhenti pada upaya penolakan, melainkan terus berupaya mengganti tatanan lain. Ketiga, kaum radikalis memiliki keyakinan kuat akan kebenaran program atau ideologi yang mereka bawa. Bagi Gellner, watak ini lebih disebabkan watak dasar high Islamsebagai kontras folk Islam-yang luar biasa monotheistik, nomokratik, dan berorientasi puritanisme dan skripturalisme. ${ }^{15}$ Menurut Fachry Ali, usaha-usaha tersebut pada akhirnya akan menimbulkan idealisasi ajaran Islam dalam bentuk ideologisasi, yakni himpunan nilai, ide, norma, dan keyakinan yang dimiliki seseorang lalu dijadikan dasar dalam menentukan sikap terhadap problem politik dan mempengaruhi tindakan politiknya juga. ${ }^{6}$ Dengan demikian, usaha-usaha menciptakan gerakan postnasionalisme yang dimainkan oleh Abdullah Sungkar dan Abu Bakar Baa'syir lewat lembaga pendidikan pesantren Al-Mukmin Ngruki adalah bentuk kritikan keras kepada pemerintah Orde Baru saat itu karena selalu melakukan intervensi terhadap umat Islam. Selain itu, paradigma postnasionalisme yang mereka usung harus diakui bertentangan dengan semangat pancasila dan banyak

\footnotetext{
15 Mustolih, Mengikis Fundamentalisme-Radikal Agama Dengan Pendidikan Islam-Pesantren di Indonesia, Jurnal Islamic Review, Volume II, No. 1 April 2013, h. 141

16 Afif Muhammad, Radikalisme Agama-agama Abad 21, Journal of Islamic Studies, Volume 41, Number 2, 2003, h. 322
}

dipengaruhi oleh kondisi Timur Tengah. Kondisi inilah yang menciptakan rasa kepedulian juga keberpihakkan kepada kelompok Jamaah Islamiyah melalui persepsi monolitik.

Upaya memahami imajinasi mereka untuk mendirikan Negara Islam di Indonesia di sisi lain bukan hanya faktor Timur Tengah (eksternal) semata melainkan faktor konstruksi sejarah masa lalu (internal). Fred R. Von der Mehden dalam "Islam and the Rise of Nationalism in Indonesia" menjelaskan bahwa Islam merupakan sarana terbaik untuk membangun rasa persatuan nasional dan perbedaan dari penjajah Belanda. Oleh sebab itu, karena terdiri dari berbagai tradisi historis, linguistik, kultural, dan bentuk geografis yang berbeda, maka satu-satunya ikatan universal yang tersedia di luar kekuasaan kolonial adalah Islam. ${ }^{17}$ Berangkat dari paradigma sejarah seperti ini, maka kelompok Islam puritan berusaha mewujudkan imajinasi mereka melalui proses kaderisasi di lembaga pendidikan, misalnya pesantren. Jika dicermati, proses-proses kaderisasi ummat yang dimainkan oleh Abdullah Sungkar dan Abu Bakar Baa'syir selalu berpijak pada keyakinan fundamental bahwa Islam mutlak terdiri dari din (agama), dunya (dunia) serta daulah (Negara). Sehingga, ketiga pilar tersebut harus diintegrasikan tanpa intervensi pihak manapun.

Pada saat yang sama, menarik jika kita membandingkan dinamika pesantren Al-Mukmin Ngruki dengan pesantren Kombos di Manado. Mengingat rentang waktu berdirinya kedua pesantren tersebut hanya berbeda 5 tahun (1972 dan 1977). Sehingga, kita dapat menganalisis melalui perspektif fenomenologis di bawah kekuasaan Orde Baru. Meskipun kalah secara nominal, umumnya dunia

\footnotetext{
17 Bahtiar Effendy, Islam dan Negara : Transformasi Pemikiran dan Praktik Politik Islam di Indonesia, (Jakarta : Paramadina, 1998), h. 63
} 
pesantren di Manado menujukkan gejala dimana nilai-nilai universal Islam dan sikap pro sosial mulai dipraktekkan. Kesadaran filosofis untuk menjalankan hidup di ruang keragaman menjadi sebuah keniscayaan di sana. Pemberontakan-pemberontakan atas nama ideologi "Islam Kaffah" nyaris sama sekali tidak terdengar. Begitu pun sebaliknya, upaya pemerintah dalam menggulingkan eksistensi pesantren di Manado akibat isu-isu radikalisme dan terorisme yang berkembang di Jawa buktinya tidak pernah terjadi. Ada indikasi kuat bahwa konsep ideal Pancasila telah menguat dalam memori kolektivitas masyarakat Manado lewat pendidikan formal/nonformal. ${ }^{18}$ Dari hasil kajian Coleman seperti yang dikutip Azyumardi Azra menjelaskan bahwa terdapat teori dominan dalam demokrasi yang mengasumsikan jika pendidikan adalah sebuah korelasi bahkan persyaratan bagi tatanan demokratis. ${ }^{19}$

\section{Pesantren Kombos Manado : Gerakan Merespons Arus Postnasionalisme}

Seperti dijelaskan di atas, situasi pesantren Kombos diManado terlihat stabil bahkan tidak terjebak dalam aksi radikal dan terorisme global seperti di pesantren Al-Mukmin, Ngruki Jawa Tengah.Pesantren Kombos selalu tampil

\footnotetext{
18 Memori kolektivitas yang positif terhadap konsep Pancasila ini tentu saja dikonstruksi oleh ideologi "Torang Samua Basudara" dan "Si Tou Tumou Timou Tou" sebagaimana dijelaskan sebelumnya. Karakter Islam di Manado memang memiliki pengalaman sejarah berbeda dengan karakter Islam di Jawa khususnya kelompok Jamaah Islamiyah ketika memaknai Pancasila. Agar mendapatkan pemahaman yang komprehensif terkait hal tersebut, lihat Faisal Ismail, Islam and Pancasila : Indonesian Politics 1945-1995, (Jakarta : Badan Litbang Agama dan Diklat Keagamaan RI, 2001).
}

19 Azyumardi Azra, Pendidikan Islam : Tradisi dan Modernisasi di Tengah Tantangan Milenium III, (Jakarta : Kencana, 2012), h. 69 ke dalam ruang publik lewat Kiai dan santri sehingga tidak mengalami deprivasi relatif, disorientasi, dislokasi dan negativisme terhadap masyarakat sekitar. Motif tampilnya mereka ke ruang publik tentu untuk menjalin spirit persatuan dan kesatuan. Hasil kajian Masykuri Abdillah menjelaskan bahwa persatuan adalah melihat kekayaan kultural sebagai suatu realitas. Sedangkan kesatuan adalah sikap yang melihat Indonesia sebagai bhineka tunggal ika. Dengan demikian, persatuan mengacu kepada politik kebudayaan, dan kesatuan mengacu kepada politik pemerintahan. ${ }^{20}$ Dalam merespons postnasionalisme, pesantren Kombos di Manado membangun tiga gerakan utama yaitu gerakan ideologi-politik, gerakan demografis-akomodatif, dan gerakan programatik-asosiatif. Tiga gerakan tersebut menggunakan pendekatan humanis, rasional, dan fungsional.

\section{Gerakan Ideologi-Politik}

Pentingnya unsur gerakan sosial dalam merespons problematika kehidupan berbangsa dan bernegara disebabkan adanya hukum everything is connected to everything else. Gerakan sosial berfungsi untuk mendiagnosis kondisi sosial yang bermasalah untuk dipecahkan, menawarkan jalan keluar dari masalah itu dan menawarkan alasan pembenar untuk memotivasi dukungan bagi aksi-aksi kolektif. ${ }^{21}$ Terkait dengan hal tersebut, pesantren Kombos memposisikan diri sebagai aliran salafiyah-modern yaitu mempertahankan

\footnotetext{
${ }^{20}$ Masykuri Abdillah, Demokrasi di Persimpangan : Makna Respons Intelektual Muslim Indonesia terhadap Konsep Demokrasi (1966-1993), (Yogyakarta : Tiara Wacana Yogya, 1999), h. 147-148

${ }^{21}$ Quintan Wiktorowicz (editors), Gerakan Sosial Islam : Teori, Pendekatan, dan Studi Kasus, (Yogyakarta : Gading Publisher, 2012), h. 21
} 
serta mengajarkan kitab-kitab klasik atau kitab kuning sebagai inti pendidikan di pesantren tetapi juga ada mata pelajaran umum yang diajarkan. ${ }^{22}$ Secara ideologi, pesantren Kombos di Manado tampaknya cenderung menganut paham "Torang Samua Basudara"23 dan "Si Tou Timou Tumou Tou"24. Sebagai contoh, efek dari peristiwa kerusuhan Poso tahun 2000 membuat pesantren Kombos juga ikut terkena dampak. Namun, KH. Rizali M. Noor segera membangun komunikasi dengan berbagai elemen masyarakat dan pemerintah. Sehingga, pesantren menjadi pusat dialog antara umat Islam dan Kristen di Manado. Salah seorang alumni pesantren menuturkan :

22 Rahman Mantu, "Pesantren PKP Kombos : Studi Sosiologis terhadap Aktivitas Pesantren di Tengah Mayoritas Masyarakat Kristen Kota Manado" dalam Muhamad Murtadlo dkk, Pesantren \& Reproduksi Ulama, (Jakarta : Pustaka Cendekia Muda, 2015), h. 45

23 Artinya, kita semua diciptakan Tuhan menjadi saudara. Saudara di sini diinterpretasikan sebagai sikap inklusif untuk menerima ragam karakter agama, ragam pemikiran budaya, maupun ragam komunitas etnik pendatang. Ketiga ragam ini kemudian menciptakan sistem "emosionalitas kebhinekaan". Ideologi "Torang Samua Basudara" dipopulerkan oleh mantan Gubernur Sulawesi Utara, E.E Mangindaan dengan mempertimbangkan faktor historis, sosiologis dan yuridis. Tentu ini sangat berbeda dengan kondisi masyarakat pesantren Al Mukmin Ngruki di Jawa Tengah yang cenderung homogen sehingga ideologi Islam murni begitu kental bahkan terkesan tidak kompromi dengan ideologi lain. Untuk memahami kondisi heterogenitas Manado, lihat Basri Amin, "Mengawal Akal Sehat Pluralisme di Manado : Pengalaman dan Pandangan 1992-2002" dalam Sepus Fatem \& M. Nasir Badu (Editor), Menuju Indonesia Berkeadilan : Cerita Keadilan di Indonesia, Jakarta : Indonesia Social Justice Network, 2013.

24 Artinya, manusia hidup untuk memanusiakan manusia yang lain. Falsafah hidup ini digagas oleh Dr. Sam Ratulangi dan diterima oleh semua kalangan agama karena mengandung nilai kebaikan universal sekaligus memiliki basis kultural bahkan mampu merawat kearifan lokal di Manado.
"Setiap kali ada kasus konflik antar agama baik itu di daerah lain atau di Manado sendiri, KH. Rizali selalu mengambil momentum, beliau menginisiasi untuk mengajak tokoh dan masyarakat non-muslim berdialog dan dialog itu selalu diselenggarakan di pesantren". 25

Merujuk kepada kenyataan ini, maka dapat dipahami bahwa dalam merespons arus postnasionalisme yang ingin menghantam keutuhan NKRI, ideologi pesantren Kombos menggunakan corak top down lalu kemudian nilai-nilai "Torang Samua Basudara" dan "Si Tou Timou Tumou Tou" itu diinternalisasikan secara bottom up. Sehingga, implikasinya terjadi sinergisitas antara KH. Rizali M. Noor, para santri dan khususnya masyarakat Manado yang sangat majemuk dan rawan konflik atas nama ideologi keagamaan. Tetapi tidak berhenti sampai di situ saja, pada tahun 2010 misalnya, KH. Rizali M. Noor (warga Nahdliyin) mencalonkan diri sebagai calon wakil walikota yang berpasangan dengan Louis Nangoy $\mathrm{SH}^{26}$ (calon walikota) periode 2010-2015. Mereka berdua berangkat dari jalur independen.

Meskipun tidak terpilih ${ }^{27}$, fenomena ini jelas menunjukkan kesadaran Kiai

\footnotetext{
25 Rahman Mantu, "Pesantren PKP Kombos : Studi Sosiologis terhadap Aktivitas Pesantren di Tengah Mayoritas Masyarakat Kristen Kota Manado"., h. 47

${ }^{26}$ Louis Nangoy SH adalah seorang tokoh dari agama Kristen Advent. Louis Nangoy SH dan KH. Rizali M. Noor sudah dikenal sebagai pasangan pluralis yang sejati. Kedua figur yang dekat dengan Bapak Pluralisme Nasional, Alm $\mathrm{KH}$ Abdurrahman Wahid ini memang sejak lama disebut sebagai sosok yang memiliki pandangan dan jiwa nasionalisme yang tinggi. Dan hal tersebut sudah dipraktekkan dalam kehidupan mereka sehari-hari.
}

27 Kandidat yang terpilih adalah Dr. Ir. Vecky Lumentut DEA (52) sebagai walikota dan Harley 
untuk membangun tatanan dunia pendidikan Islam melalui jalur politik lokal di Manado. Tindakan KH. Rizali M. Noor ini memiliki relevansi teologis dengan QS Ali Imran :110. Memang ada pro kontra terkait pencalonannya. Kelompok yang kontra menganggap jika dia terpilih maka tanggungjawab di pesantren akan diabaikan. Tapi, bagi yang pro, sebetulnya langkah yang diambilnya sudah tepat agar ada wakil muslim yang akan membuat, menentukan dan mengawal kebijakan-kebijakan pendidikan Islam dengan semangat toleran, moderat, inklusif dan memberdayakan pluralitas. Agenda ini disebabkan dalam konteks pendidikan nasional, pendidikan agama cenderung dipahami sebagai pelajaran khusus agama tertentu saja. Dan ketika agama-agama lain diajarkan, mereka selalu menggunakan perspektif satu agama. Model pendidikan agama eksklusif seperti ini menjadi tantangan terutama setelah reformasi politik tahun 1998. Sejauh ini, kebijakan pemerintah terkait model pendidikan agama tersebut belum ada perubahan yang signifikan. ${ }^{28}$ Semua semangat Pancasila ini tentu saja tidak terlepas dari ideologi awal yang terbangun di pesantren Kombos Manado. $^{29}$

Mangindaan SE MSM (35) sebagai wakil walikota. Keduanya berasal dari Partai Demokrat.

${ }^{28}$ Zainal Abidin Bagir \& Irwan Abdullah, "The Development and Role of Religious Studies : Some Indonesian Reflection", dalam Kamaruzzaman Bustamam-Ahmad \& Patrick Jory (editors), IslamicStudies and Islamic Education in Contemporary Southeast Asia, (Kuala Lumpur : Yayasan Ilmuwan, 2011), h. 62

${ }^{29}$ Ideologi Islam yang diprioritaskan di Pesantren Kombos ini bertolak belakang dengan ideologi Islam yang diterapkan di Pesantren Al-Mukmin Ngruki. Berdasarkan catatan Muhamad Wildan, "Kajian-kajian kitab yang diadakan secara informal di Pondok Ngruki secara simultan membentuk pola pikir para santri. Beberapa kitab karya tokoh-tokoh pergerakan Ikhwanul Muslimin di Mesir seperti Fathi Yakan, Sayyid Qutb dan Hassan Al-Banna dikaji secara tidak
Jika membaca gerakan ideologis-politis KH. Rizali M. Noor, maka jalur politik merupakan alat untuk menyukseskan penyelenggaraan pendidikan. Meskipun kesuksesan penyelenggaraan pendidikan bukan hanya menjadi tugas dan tanggungjawab pemerintah saja melainkanjuga masyarakat, namun pemerintahlah yang memiliki infrastruktur dan suprastruktur yang lebih kuat dalam memikul tugas dan tanggungjawab terselenggaranya pendidikan yang humanis. Tapi, pengaruh Kiai tidak permanen karena sangat dipengaruhi olehpilihan-pilihan politik mereka. $^{30}$ Jika misi politik Kiai tidaksesuai dengan ulama NU, apalagi bersikap oportunis-matrealistis,maka dirinya akan tenggelam. Di sinilah letak korelasi positif antarapesantren dan politik NU. Pesantrenmembutuhkan kebijakan politik agar efektif dan efisien. Sedangkan politik NU membutuhkan ilmu pengetahuan agar tidak salah jalan. Dari usaha politik pemerintahan dan kepesantren-an yang dijalankan oleh $\mathrm{KH}$. Rizali M. Noor jelas menggambarkan gerakan guna merespons arus postnasionalisme agar tidak masuk ke Manado meski secara teritori Sulawesi Utara berbatasan dekat dengan wilayah Poso dan Mindanao, Philipina Selatan.

formal di luar kelas secara sorogan ataupun secara berkelompok (bandongan). Kitab Al-Wala' wa alBara' karya Said salim al-Qahthani dan Tarbiyah Jihadiyah karya Abdullah Azzam juga dipakai dalam kajian-kajian umum atau khusus. Akhirnya, kajian kitab ini ikut berperan dalam merekonstruksi paradigma santri akan sikap religiusitas dan menentang nasionalisme yang tidak sesuai dengan ajaran Islam kaffah. Meskipun, terminologi "kaffah" di sini masih perlu dikontekstualisasikan dengan realitas masyarakat Indonesia yang tidak sama persis dengan di Timur Tengah. Lihathttps://wildan71.wordpress.com/2010/09/26/ pondok-ngruki-dan-radikalisme-agama-diindonesia/. Diakses 13/11/2016.

${ }^{30}$ Laode Ida, NU Muda : Kaum Progresif dan Sekularisme Baru, (Jakarta : Erlangga, 2004), h. 5-7 
Dimana, tempat itu adalah salah satu markaz utama Jamaah Islamiyah di bawah komando Abu Bakar Baa'syir dan Abdullah Sungkar.

\section{Gerakan Demografis-Akomodatif}

Selain melakukan gerakan ideologipolitik, pesantren Kombos di Manado juga mengambil langkah kedua yakni melalui gerakan demografis-akomodatif. Gerakan demografis adalah selama ini tampaknya pesantren mulaimempelajari dinamika kependudukan meliputi ukuran, kriteria, distribusi penduduk serta menganalisis perubahan jumlah penduduk akibat adanya proses transmigrasi.Hal ini dapat dipahami sebagai upaya pesantren untuk mengontrol peserta didik (santri) yang akan masuk ke lembaga pendidikan Islam tersebut. Dengan demikian, pesantren mengambil kebijakan untuk menyeleksi dengan ketat terutama terhadap santri pindahan dari luar Sulawesi Utara. Agar, ideologi-ideologi Islam garis keras tidak disebarkan pada pesantren tersebut secara terstruktur, sistematis dan masif. Apalagi, pesantren Kombos hanya menerima santri lelaki saja. Dan dalam banyak kasus, pelaku tindak radikalisme maupun terorisme untuk mencederai nasionalisme berasal dari dari kaum pria.

Meski bertindak selektif, pesantren Kombos juga melakukan tindakantindakan akomodatif kepada masyarakat pribumi maupun pendatang yang ingin memasukkan putra-putri mereka ke pesantren. Meminjam pemikirannya Kluckhohn, maka pesantren Kombos di Manado memiliki pola hubungan yang bercorak horizontal oriented. Pola hubungan ini lebih mementingkan keharmonisan dengan sesama karena hal ini dianggap sangat penting dan berharga dalam hidup. ${ }^{31}$ Senada dengan itu,

\footnotetext{
${ }^{31}$ Nilai-nilai Kepercayaan Masyarakat Tentang Ruang Tempat Tinggal di Kota Manado, (Jakarta : Departemen Kebudayaan dan Pariwisata
}

Kriesberg menjelaskan, "Semakin tinggi tingkat interaksi dan saling ketergantungan antar pihak-pihak yang tadinya berkonflik akan semakin membatasi munculnya konflik baru". ${ }^{32}$ Dalam perspektif masyarakat multikultur seperti Manado, yang namanya keanekaragaman tidak bisa diabaikan begitu saja. Keanekaragaman adalah fakta yang tidak dapat dielakkan dalam kehidupan kolektif. Penghormatan kepada orang luar juga menumbuhkan rasa kesetiaan, memberi rasa percaya diri dan keberanian untuk berinteraksi dengan kebudayaan-kebudayaan lain serta memudahkan integrasi ke dalam masyarakat yang lebih besar.

Berdasarkan kajian Wekke, pesantren Kombos adalah pilar dinamis dalam membentuk sinergisitas masyarakat. Pendidikan Islam di sana mencerminkan sikap mulia dalam berkomunikasi di ruang keragaman. Pesantren yang ditemukan di daerah Protestan dan Katolik itu bekerjasama dengan mempercayai agama lain pada setiap kegiatan yang beragam. Selain itu, ada banyak program untuk mendorong komunikasi antarindividu melalui pilihan agama yang berbeda. Akhirnya, pesantren merupakan tanda damai sebagaimana inti utama Islam. Pesantren memberikan kontribusi kepada daerah walaupun mereka berada di masyarakat yang berbeda. ${ }^{33}$ Sampai di sini, kita dapat melihat bahwa gerakan demografisakomodatif yang dilakoni pesantren Kombos dalam merespons arus postnasionalisme di Manado jelas

Direktorat Jenderal Nilai Budaya, Seni dan Film, 2005), h.115

32 Tri Ratnawati, Maluku : Dalam Catatan Seorang Peneliti, (Yogyakarta : Pustaka Pelajar, 2006), h. 1

33 Ismail Suardi Wekke, Lembaga Pendidikan Islam Sebagai Pilar Dakwah di Wilayah Minoritas Muslim, Jurnal Dakwah Al-Hikmah, Vol. 4 (2) 2013, h. 1 
membuktikan kepedulian sekaligus keberpihakkan terkait bagaimana merawat keutuhan religiusitas dan nasionalisme secara proporsional. Peran para alumni pun turut membantu dalam memelihara agar atmosfer kedamaian tetap terjaga pada almamater mereka. Alumni pesantren Kombos telah tersebar ke berbagai sektor pekerjaan. Ada yang menjadi Guru SMA, Dosen, maupun pejabat di Kantor Kementerian Agama yang tersebar di Sulawesi Utara.

Karakter pesantren Kombos yang lekat dengan jiwa kosmopolitan ini lebih disebabkan kondisi Manado sejak pesantren ini didirikan pada tahun 1977 tidak pernah mengalami ketegangan dengan pemerintah pusat di bawah kekuasaan Orde Baru. Selain itu, potret wilayah yang heterogen juga membuat masyarakat setempat maupun pendatang lebih berhati-hati dalam menonjolkan ideologi agama, etnis atau budaya masing-masing. Mereka lebih memilih bersikap komplementer daripada substitusi. Pada era Orde Baru, sebagian besar orang Indonesia dan sebagian besar Muslim_khususnya di Manadotampaknya cukup nyaman dengan dukungan negara bagi agama dalam kehidupan publik. ${ }^{34} \mathrm{Di}$ sisi lain, umat Islam di sana juga sepanjang pengamatan penulis kurang begitu menaruh simpati terhadap gerakan radikalisme maupun terorisme meskipun menggunakan alasan agama maupun dalil bahwa demokrasi di Indonesia sudah rusak dan pantas digantikan dengan sistem agama tertentu sebagaimana yang dialami oleh kelompok Jamaah Islamiyah bersama kelompoknya di Jawa Tengah. Tidak lupa pula, para Kiai NU lain di Manado yang turut mengembangkan pesantren Kombos seperti KH. Fauzi Nurani, KH. Abdul Wahab Abdul Gafur, dan KH.

34 Robert W. Hefner, (editors), Politik Multikulturalisme : Menggugat Realitas Kebangsaan, (Yogyakarta : Impulse, 2007), h. 68
Abdurrahman Latukau Lc, tidak menjalin sama sekali hubungan serta mendukung gerakan Islam Transnasional yang terus memperjuangkan berdirinya Negara Islam.

Respons yang diberikan para Kiai di Manado tersebut menunjukkan sikap yang egaliter dalam memandang NKRI. Jika dilacak, maka paradigma mereka sejalan dengan pemikiranSoepomo. Ia menjelaskan bahwa mendirikan Negara Islam di Indonesia berarti tidak akan mendirikan negara persatuan. Mendirikan negara Islam di Indonesia berarti mendirikan negara yang mempersatukan diri dengan golongan terbesar yaitu Islam. Kalau demikian, maka tentu akan timbul "minderheiden", soal golongan agama yang kecil-kecil, golongan agama Kristen dan lain-lain. Golongan agama kecil itu tentu tidak bisa mempersatukan dirinya dengan negara. ${ }^{35}$ Sebagai wujud apresiasi terhadap peran Kiai dan pesantren di Manado, Dr. Sinyo Harry Sarundajang (mantan Gubernur Sulawesi Utara) mengungkapkan bahwa ikatan batin dengan segenap ormas Islam dan umatnya di daerah ini sangat mesra dan berkesinambungan. Sinyo juga menyampaikan penghargaan kepada Ulama dan tokoh agama dalam menjaga kerukunan antar umat beragama terutama yang berkaitan dengan radikalisme.

\section{Gerakan Program-Asosiatif}

Adapun langkah terakhir yang dilakukan pemerintah daerah dengan melibatkan tokoh-tokoh agama dari pesantren di Manado dalam merespons arus postnasionalisme adalah gerakan programatik-assosiatif. Program di sini berarti usaha konsolidasi antar pihak yang memiliki pengaruh untuk memobilisasi massa. Program tersebut

\footnotetext{
35 Yudi Latif, Negara Paripurna : Historisitas, Rasionalitas, dan Aktualitas Pancasila, (Jakarta : Kompas Gramedia, 2012), h.71
} 
misalnya terlihat pada tahun 2016, dimana Kodim 1309/Manado menggelar sosialisasi radikalisme dan terorisme. Beberapa solusi yang coba mereka sampaikan sebagai berikut. Pertama, nilai kebangsaan harus dibentuk melalui kurikulum pendidikan.Kedua, pemantapan wawasan kebangsaan harus dilaksanakan melalui sosialisasi dan pelatihan. Ketiga, penanaman nilai wawasan kebangsaan harus dilakukan lewat kaderisasi. ${ }^{36}$

Sedangkan pada tahun yang bersamaan, digelar pula seminar dan dialog terkait pelibatan media massa dalam pencegahan radikalisme dan terorisme. Gubernur Sulawesi Utara, Olly Dondokambey SE menjelaskan media mempunyai andil besar dalam pencegahan tindak intoleran tersebut. Aspek kontraradikalisme media massa menjadi mitra dari bidang kontrapropaganda. Selain itu, Forum Koordinasi Pencegahan Terorisme (FKPT) Sulawesi Utara diajak untuk bersinergi dengan pemerintah daerah. ${ }^{37}$ Dua agenda kerja di atas menunjukkan bahwa seluruh elemen masyarakat Manado sendiri sangat mengantisipasi kemungkinan berdiasporanya paham postnasionalisme.

Seperti dijelaskan sebelumnya, secara geografis, letak Sulawesi Utara tidak begitu jauh dengan Mindanao dan Poso. Pulau Miangas di Kabupaten Talaud merupakan pintu gerbang masuk ke wilayah Philipina Selatan, sedangkan Gorontalo (sebelum menjadi daerah otonom pada 2001) merupakan pintu gerbang masuk ke wilayah Poso,

36 Diakses melalui kodim 1309.kodam-
wirabuana.mil.id/2016/07/22/kodim-
1309manado-gelar-sosialisasi-radikalisme-dan-
terorisme. Diakses Selasa, 06 September 2016

37 Diakses melalui www.gomanado.com/2016/06/08/13075/terkaitradikalisme-dan-terorisme-gubernur-sulut-persharus-menyajikan-berita-yang-seimbang/. Diakses Selasa, 06 September 2016.
Sulawesi Tengah. Dua wilayah ini adalah bagian utama dari markas Jamaah

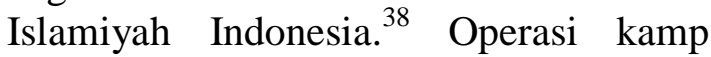
pelatihan Jamaah Islamiyah di Mindanao bernama Hudaibiyah yang dikontrol langsung oleh majelis qiyadah. Pada 1997, Musthapa memimpin mantiqi III di wilayah Malaysia Timur, Kalimantan Timur, Sulawesi Tengah dan Mindanao. Dan pada 2001, Nasir Abas menggantikannya. Nasir cukup berhasil dalam mempersiapkan wilayahnya sebagai pendukung askari. Itu dibuktikan dengan dibukanya kamp-kamp pelatihan paramiliter di Poso. ${ }^{39}$ Mencermati pergerakan mereka ini, tentu membuat banyak pihak yang peka akan mengambil tindakan preventif agar ideologi Islam garis keras tersebut tidak sampai berkembang di Sulawesi Utara. Oleh sebab itu, pemerintah daerah bersama polisi, tentara, tokoh masyarakat serta tokoh agama menciptakan koordinasi secara matang. Contoh, konkret dari kinerja ini misalnya membuat pemerintah Philipina membuka Konsulat Jenderal Philipina di Jalan 17 Agustus Manado.

\footnotetext{
${ }^{38}$ Pulau Sulawesi dan Mindanao merupakan wilayah geopolitik tunggal yang mempengaruhi stabilitas politik di kawasan Asia Tenggara dengan kondisi maritim yang lebih besar. Batas daerah ini terkait erat dengan pembajakan, milisi bersenjata, teroris, dan kelompok separatis. Luasnya daerah di Sulawesi Tengah, Sulu, Tawi-Tawi, Maguindanao, Lanao del Sur, Lanao del Norte, Utara dan Selatan Cotabato, Sultan Kudarat, serta perairan yang berdekatan dengan daerah-daerah tersebut merupakan daerah yang tidak berpemerintahan. Selain itu, ruang diantara kedua pulau ini (SulawesiMindanao) tampaknya menjadi koridor logistik utama bagi kelompok teroris Jamaah Islamiyah dan kelompok-kelompok ekstremis lainnya.Lihat Angel Rabasa et.al., Undergoverned Territories : Understanding and Reducing Terrorism Risk, (Pittsburgh : RAND Corporation, 2007), h. 111

${ }^{39}$ As'ad Said Ali, Al-qaeda : Tinjauan SosialPolitik, Ideologi dan Sepak Terjangnya, h.168170
} 
Program pencegahan aktivitas radikalisme dan terorisme di atas dikuatkan lagi dengan pola relasi assosiatif antar masyarakat dan pemerintah pusat-daerah.Relasi asosiatif merupakan hubungan sosial yang dinamis antar orang perorangan maupun antar kelompok.Terbentuknya relasi asosiatif adalah sebagai pengaruh timbal balik di antara mereka dalam usaha memecahkan persoalan yang diharapkan dan dalam usaha untuk mencapai tujuan bersama.Faktor pendorong relasi asosiatif adalah adanya kontak sosial melalui komunikasi secara langsung atau melalui media. Salah satu media yang penting disebut dalam konteks ini ialah Radio RAL 102.8 FM. Radio RAL FM terletak di Jalan Hasanudin No. 20, Sindulang, Manado. Radio yang berdiri sejak tahun 1994 ini aktif menyampaikan dakwah Islam, membangun budaya dan pola pikir, serta memperkuat rasa persatuan serta kesatuan masyarakat setempat. Radio tersebut memiliki audiens yang cukup banyak dari berbagai usia.

Di sisi lain, media tersebut merupakan kekuatan pesantren Kombos untuk menyampaikan pesan-pesankeagamaan karena jaraknya yang tidak begitu jauh. Usaha ini misalnya telah dilakukan oleh Ali Thalib, salah satu Qori' asli Manado yang sering mengajar pengajian di pesantren Kombos. Sepintas, Radio RAL FM berbeda dengan Radio ABC dan Radio Dakwah Islamiyah (RADIS)yang dikelola Abdullah Sungkar serta Abu Bakar Baa'syir melalui pesantren AlMukmin Ngruki karena menganut ideologi Islam transnasional. Lantas, segera dibredel oleh pemerintah Orde Baru.Relasi assosiatif dibangun atas pendekatan humanis, rasional serta fungsional. Pendekatan humanis adalah nilai-nilai kemanusiaan harus tetap di kedepankan dalam berbagai konflik yang terjadi apalagi telah menyangkut persoalan ideologi agama. Pendekatan rasional adalah sikap kritis-objektif harus tetap dijadikan perangkat epistemologis dalam memahami fenomena sosial. Sehingga, hasilnya tidak bias. Sedangkan pendekatan fungsional adalah semua perilaku manusia diarahkan kepada asas kegunaan secara praktis. Agar, konflikkonflik dengan mudah dapat diminimalisir.

\section{Penutup}

Eksistensi antara pesantren Al-Mukmin Nguri di Solo, Jawa Tengah dan pesantren Kombos, di Manado, Sulawesi Utara memiliki dinamika yang berbeda. Pesantren Al-Mukmin lebih menjadikan ajaran Islam untuk kepentingan ideologi sekaligus aksi gerakan kolektif terkait bagaimana menegakkan syariat Islam bahkan Darul Islam Indonesia yang jelas bertentangan dengan Pancasila maupun UUD 1945. Tapi, pesantren Kombos lebih menjadikan ajaran Islam itu untuk sumber ilmu pengetahuan agar dapat berkontribusi secara demokratis terhadap tatanan masyarakat muslim di Sulawesi Utara. Perbedaan masing-masing pesantren yang muncul bersamaan pada era Orde Baru ini disebabkan latar belakang sosiol-kultural, jaringan keilmuan, orientasi politik serta basis pergerakan. Untuk merespons arus postnasionalisme tersebut, pesantren Kombos di Manado melakukan tiga gerakan utama yaitu ideologis-politis, demografis-akomodatif, dan programassosiatif. Gerakan seperti ini memang perlu dilakukan secara terus menerus bersama pemerintah pusat-daerah, aparat keamanan, tokoh masyarakat, tokoh agama, kalangan akademisi sekaligus praktisi lokal. Karena sekali lagi, secara geografis, Sulawesi Utara sangat berdekatan dengan dua lokasi yang merupakan markas dari Jamaah Islamiyah tersebut. 


\section{Daftar Pustaka}

Abdillah, Masykuri 1999. Demokrasi di Persimpangan : Makna Respons Intelektual Muslim Indonesia terhadap Konsep Demokrasi (1966-1993), Yogyakarta : Tiara Wacana Yogya.

Abduh, Umar (editors), 2003. Konspirasi Intelijen \& Gerakan Islam Radikal, Jakarta:Center for Democracy and Social Justice Studies.

Ahyar, Muzayyin 2015. Membaca Gerakan Islam Radikal dan Deradikalisasi Gerakan Islam, Jurnal Walisongo, Volume 23, Nomor 1, Mei.

Azra, Azyumardi 2012. Pendidikan Islam : Tradisi dan Modernisasi di Tengah Tantangan Milenium III, Jakarta : Kencana.

Bagir, Zainal Abidin Bagir \& Abdullah, Irwan, "The Development and Role of Religious Studies : Some Indonesian Reflection”, in Kamaruzzaman Bustamam-Ahmad \& Patrick Jory (editors), 2011.IslamicStudies and Islamic Education in Contemporary Southeast Asia, Kuala Lumpur : Yayasan Ilmuwan.

Bruinessen, Martin van. "Tradisionalist and Islamist Pesantrens in Contemporary Indonesia" in Farish A. Noor, Yoginder Sikand \& Martin van Bruinessen (editors) 2008, The Madrasah in Asia : Political Activism and Transnational Linkages, Amsterdam : Amsterdam University Press.

Effendy, Bahtiar 1998. Islam dan Negara : Transformasi Pemikiran dan Praktik Politik Islam di Indonesia, Jakarta : Paramadina.

Hasan, Noorhaidi, 2008. Laskar Jihad : Islam, Militansi, dan Pencarian Identitas di Indonesia Pasca-Orde Baru, Jakarta : LP3ES.

Hefner, Robert W. (editors), 2007. Politik Multikulturalisme : Menggugat Realitas Kebangsaan, Yogyakarta : Impulse.

Hefner, Robert W. 2009. Making Modern Muslims : The Politics of Islamic Education in Southeast Asia, Honolulu : University of Hawaa'i Press.

Http://kodim 1309.kodam-wirabuana.mil.id/2016/07/22/kodim-1309manado-gelar-sosialisasiradikalisme-dan-terorisme. Diakses Selasa, 06 September 2016

Http://manadokota.bps.go.id/linktabel statis/view/id/34. Diakses Selasa 06 September 2016.

Http://www.gomanado.com/2016/06/08/13075/terkait-radikalisme-dan-terorisme-gubernursulut-pers-harus-menyajikan-berita-yang-seimbang/. Diakses, Selasa, 06 September 2016.

Https://wildan71.wordpress.com/2010/09/26/pondok-ngruki-dan-radikalisme-agama-diindonesia/. Diakses 13/11/2016.

Ida, Laode 2004. NU Muda : Kaum Progresif dan Sekularisme Baru, Jakarta : Erlangga. 
Latif, Yudi 2012. Negara Paripurna : Historisitas, Rasionalitas, dan Aktualitas Pancasila, Jakarta : Kompas Gramedia.

Makello, Ilham Daeng, 2010. Kota Seribu Gereja : Dinamika Keagamaan Dan Penggunaan Ruang Di Kota Manado, Yogyakarta : Penerbit Ombak.

Mantu, Rahman"Pesantren PKP Kombos : Studi Sosiologis terhadap Aktivitas Pesantren di Tengah Mayoritas Masyarakat Kristen Kota Manado” dalam Muhamad Murtadlo dkk, 2015.Pesantren \& Reproduksi Ulama, Jakarta : Pustaka Cendekia Muda.

Muhammad, Afif 2003. Radikalisme Agama-agama Abad 21, Journal of Islamic Studies, Volume 41, Number 2.

Mustolih, 2013. Mengikis Fundamentalisme-Radikal Agama Dengan Pendidikan IslamPesantren di Indonesia, Jurnal Islamic Review, Volume II, No. 1 April.

Nilai-nilai Kepercayaan Masyarakat Tentang Ruang Tempat Tinggal di Kota Manado, 2005. Jakarta : Departemen Kebudayaan dan Pariwisata Direktorat Jenderal Nilai Budaya, Seni dan Film.

Rabasa, Angel et.al., 2007. Undergoverned Territories : Understanding and Reducing Terrorism Risk, Pittsburgh : RAND Corporation.

Ratnawati, Tri 2006. Maluku : Dalam Catatan Seorang Peneliti, Yogyakarta : Pustaka Pelajar.

Said Ali, As'ad 2014. Al-qaeda : Tinjauan Sosial- Politik, Ideologi dan Sepak Terjangnya, Jakarta : LP3ES.

Sallataholy, Fahmi 2012. Pelabelan Gerakan Radikal Bagi Kelompok Keagamaan Dalam Islam : Studi Relasi Agama dan Negara di Indonesia, Dialog, Jurnal Penelitian dan Kajian Keagamaan, Vol. 35, No. 1, Juni.

Subhan, Arief 2012. Lembaga Pendidikan Islam Indonesia Abad ke-20 : Pergumulan antara Modernisasi dan Identitas, Jakarta : Kencana.

Sunarwoto, 2013. "Dakwah radio in Surakarta : A contest for Islamic Identity", in Jajat Burhanuddin and Kees van Dijk (editors), Islam in Indonesia : Contrasting Images and Interpretation, Amsterdam : Amsterdam University Press.

Wekke, Ismail Suardi 2013. Lembaga Pendidikan Islam Sebagai Pilar Dakwah di Wilayah Minoritas Muslim, Jurnal Dakwah Al-Hikmah, Vol. 4 (2).

Wiktorowicz, Quintan (editors), 2012. Gerakan Sosial Islam : Teori, Pendekatan, dan Studi Kasus, Yogyakarta : Gading Publisher. 